\title{
Antibiotic susceptibility of Mycoplasma fermentans strains from various sources and the development of resistance to aminoglycosides in vitro
}

\author{
P. C. T. HANNAN
}

Mycoplasma Experience Ltd, 1 Norbury Road, Reigate, Surrey RH2 $9 B Y$

\begin{abstract}
Summary. Mycoplasma fermentans strains reputedly from human infections or tissue culture cells were much more susceptible to azithromycin than to clarithromycin or erythromycin. Lincomycin, clindamycin and several tetracyclines also exhibited good mycoplasmastatic activity but mycoplasmacidal concentrations were substantially greater than the MICs. Ciprofloxacin was the most active of three fluoroquinolones tested and was mycoplasmacidal at concentrations close to the MIC. Tiamulin and mupirocin were also very active. Synergy with specific $M$. fermentans antiserum plus guinea-pig complement was not observed with any class of antibiotic although the number of viable mycoplasmas was markedly reduced by the combined immunological components. Marked differences in susceptibility to various aminoglycosides were observed. Human strains isolated in cell-free media up to 1967 were aminoglycoside susceptible (MIC range $0.5-25 \mathrm{mg} / \mathrm{L}$ ) but recent human isolates and strains isolated from tissue culture cells often showed either single or multiple aminoglycoside resistance (MIC $>500 \mathrm{mg} / \mathrm{L}$ ). Two aminoglycoside-susceptible strains developed resistance to streptomycin or neomycin $(>500 \mathrm{mg} / \mathrm{L}$ ) within five passages in broth containing streptomycin or neomycin, respectively. Resistance to tobramycin, kanamycin or gentamicin emerged after seven, eight and 14 cycles of exposure to the respective antibiotic. Streptomycin resistance was associated with a five-fold increase in resistance to tobramycin. Neomycin-, kanamycin-, gentamicin- and tobramycin-resistant variants showed mutual cross-resistance but remained susceptible to streptomycin. Induced resistance persisted for at least 17 passages in aminoglycoside-free broth. The use of aminoglycosides in human medicine and the frequent inclusion of some of these drugs in tissue cell cultures to combat bacterial and mycoplasmal contamination might account for the aminoglycoside resistance of recent $M$. fermentans isolates.
\end{abstract}

\section{Introduction}

Mycoplasma fermentans was first isolated in $1950^{1}$ from the genital mucosa of human patients with ulcerative balanitis. These strains were named " $G$ " strains and were found to cause arthritis experimentally in mice. Subsequently $M$. fermentans was isolated from the bone marrows of leukaemic patients ${ }^{2}$ and from the joints of patients with rheumatoid arthritis. ${ }^{3}$ These strains caused a leukaemia-like disease and death $^{2,4}$ and recurrent mild arthritis ${ }^{5}$, respectively, in mice but their role in human disease is unresolved. Further attempts to isolate $M$. fermentans from rheumatoid patients have generally been unsuccessful ${ }^{6-9}$ and its role in rheumatoid arthritis remains unproven.
Since $M$. fermentans is also a contaminant of tissue culture cells ${ }^{10}$ and may be refractory to antibiotic treatment, great caution is needed before assigning a pathogenic role to this mycoplasma when cell cultures have been used during the isolation process.

The incognitus strain of $M$. fermentans was isolated from NIH/3T3 cells during transfection studies with DNA extracted from Kaposi's sarcoma tissue from a patient with AIDS. ${ }^{11}$ The culture was shown subsequently to be lethal for silvered leaf monkeys. ${ }^{12}$ The organism has been demonstrated in the tissues of nonAIDS patients with a lethal "flu-like" illness; ${ }^{13}$ it has also been isolated from the respiratory tracts of nonAIDS patients with acute respiratory disease ${ }^{14}$ and from children with community-acquired pneumonia. ${ }^{15}$ Use of the polymerase chain reaction has indicated a much higher prevalence of $M$. fermentans in human 
immunodeficiency virus 1 (HIV-1) seropositive and seronegative patients than had been supposed previously. ${ }^{16} M$. fermentans (incognitus) enhances the cytotoxic effect of $\mathrm{HIV}-1$ on $\mathrm{CD}_{4}{ }^{+}$lymphocytes in culture $^{17}$ and this can be reduced significantly by nontoxic doses of various tetracyclines, ${ }^{18}$ suggesting a possible co-factor role for $M$. fermentans in the pathogenesis of AIDS.

Information on the antibiotic susceptibility of $M$. fermentans strains is limited. ${ }^{14,19-22}$ In the present study the susceptibility to various antimycoplasma drugs of strains of $M$. fermentans isolated over many years was investigated. The possibility of synergy between certain antibiotics and specific $M$. fermentans antibodies in the presence of guinea-pig complement and the development of resistance to aminoglycosides in vitro was also studied.

\section{Materials and methods}

\section{M. fermentans strains}

" $\mathrm{G}$ " strains of $M$. fermentans were obtained from the National Collection of Type Cultures (NCTC), 61 Colindale Avenue, London (PG-18: NCTC 10117) and from the American Type Culture Collection, Rockville, MD, USA (ATCC 15474). Both were isolated in cell-free media in 1950 from human cases of ulcerative balanitis. M. fermentans strains KL4 and KL8 were obtained from Dr M. H. Williams (Arthur Stanley Institute of Rheumatology, London) in 1972. These were isolated in cell-free media in 1967 from patients with rheumatoid arthritis. M. fermentans strains E10 and Z62 were obtained from $\mathrm{Dr}$ W. H. Murphy (University of Michigan, School of Medicine, Ann Arbor, MI, USA) and were isolated from bone marrow samples from leukaemic patients between 1961 and 1966 with the aid of tissue culture cells. Strains GIM (human joint isolate) and BRO (human urethral isolate) were obtained from Professor C. Bébéar (University of Bordeaux 11, France) and were isolated in cell-free media in 1992. M. fermentans incognitus originally isolated $c .1989$ was kindly supplied by Dr S.-C. Lo (Department of Defense, Armed Forces Institute of Pathology, Washington DC, 203066000 , USA). Strains 2059, A6, F3A, C5 and 28 AC were supplied by Dr G. D. Windsor and Helena M. Windsor (Mycoplasma Experience Ltd) and were isolated from tissue culture cells from various European sources between 1982 and 1992.

\section{Mycoplasma media (modified Hayflick's) ${ }^{23}$}

Mycoplasma broth medium ${ }^{24}$ consisted of sterile Heart Infusion Broth (Difco) $90 \mathrm{ml}$, heat inactivated $\left(1 \mathrm{~h}\right.$ at $56^{\circ} \mathrm{C}$ ) horse serum (Tissue Culture Services Ltd) $20 \mathrm{ml}$, fresh yeast extract $10 \mathrm{ml}, 10 \%$ aqueous glucose $10 \mathrm{ml}$; phenol red and ampicillin were added to give final concentrations of $0.004 \%$ and $2.5 \mathrm{mg} / \mathrm{ml}$, respectively. The medium was adjusted to $\mathrm{pH} 7.8$ with sterile $1 \mathrm{~N} \mathrm{NaOH}$. Solid mycoplasma medium was prepared by adding $1.4 \mathrm{~g}$ of purified agar (Oxoid) to $90 \mathrm{ml}$ of heart infusion broth before autoclaving $(15 \mathrm{lb} / 15 \mathrm{~min})$. The remainder of the broth components were added after cooling. Thallium acetate $0.025 \%$ was added to the agar medium to combat bacterial and mould contamination.

\section{Preparation of $M$. fermentans stock cultures}

$M$. fermentans strains were grown aerobically in modified Hayflick's broth. Cultures were incubated at $36^{\circ} \mathrm{C}$ until an acid colour shift to $c$. pH 6.8 occurred, and were then frozen at $-70^{\circ} \mathrm{C}$ in $2 \mathrm{ml}$ portions. Viable counts were done on thawed samples of each $M$. fermentans strain and identities were checked by the growth inhibition test ${ }^{25}$ with specific $M$. fermentans PG-18 antiserum. The bacterial purity of each culture was determined by plating on mycoplasma agar without inhibitors and incubating the plates aerobically and anaerobically at $36^{\circ} \mathrm{C}$ for at least 4 days.

\section{Sources and preparation of antimicrobial agents}

With the exception of clarithromycin, (Klaricid, Abbott), azithromycin (Zithromax, Pfizer), ofloxacin (Tarivid, Hoechst), tiamulin hydrogen fumarate (Sandoz), chloramphenicol (Aldrich) and mupirocin (SmithKline Beecham), all other antimicrobial drugs were obtained from the Sigma Chemical Company. Most of the drugs were dissolved in de-ionised water to achieve a concentration of $1 \mathrm{mg} / \mathrm{ml}$ and sterilised by membrane filtration $(0.22 \mu \mathrm{m}$ pore size). Erythromycin, clarithromycin and azithromycin were dissolved or suspended in aqueous ethanol $10 \% \mathrm{v} / \mathrm{v}$. The fluoroquinolones apart from ciprofloxacin hydrochloride, which is water soluble, were first dissolved in sterile $0.1 \mathrm{~N} \mathrm{NaOH}$ and were then made up to volume with de-ionised water before sterilisation. Further drug dilutions were prepared at four times the required concentration in modified Hayflick's broth to allow for further dilution by other test components in the MIC tests.

\section{Immunological reagents}

$M$. fermentans PG-18 antiserum, raised in rabbits, was kindly supplied by Dr G. D. Windsor (Mycoplasma Experience Ltd). This antiserum showed specific activity against $M$. fermentans in the growth inhibition test with a 3-mm zone of inhibition against the homologous strain (PG-18), and an antibody titre of 32 in the metabolic inhibition test ${ }^{26}$ after heat inactivation $\left(30 \mathrm{~min}\right.$ at $56^{\circ} \mathrm{C}$ ). Normal rabbit serum (Sigma) was also heat inactivated before use. Lyophilised guinea-pig complement (ICN Biomedicals Inc.) was reconstituted according to the manufacturer's instructions. Dilutions of these reagents were prepared in Hayflick's broth for use in the minimal 
inhibitory and minimum mycoplasmacidal concentration (MIC and MMC) tests. In preliminary studies, the anti-mycoplasma titres against $M$. fermentans PG18 in the metabolic inhibition test were: normal rabbit serum <4; guinea-pig complement, 8-16. The dilutions of $M$. fermentans PG-18 antiserum and guinea-pig complement that just allowed mycoplasmal growth when used in combination were determined in checkerboard tests and were found to be 1 in 128 and 1 in 64 , respectively. These concentrations of antiserum and complement were used in antibiotic synergy studies.

\section{MIC and MMC tests}

MIC tests were performed in 96-well microtitration plates (Costar UK Ltd) by a modification of the broth dilution method. ${ }^{27}$ Antimicrobial agents were diluted in Hayflick's broth (pH 7.8) and $0.05 \mathrm{ml}$ of each drug dilution was added to separate wells. After addition of $0.1 \mathrm{ml}$ of Hayflick's broth, each well was inoculated with $0.05 \mathrm{ml}$ of broth containing between $10^{3}$ and $10^{6} \mathrm{cfu} / \mathrm{ml}$ of the appropriate $M$. fermentans strain. A drug-free, growth control, a sterility control and an end-point $(\mathrm{pH} 6.8)$ control were included with each plate. Plates were sealed with adhesive tape and incubated aerobically at $36^{\circ} \mathrm{C}$. Initial MICs were recorded when the colour of the growth control matched that of the end-point control, $a \geqslant 50 \%$ colour change denoting the MIC. Final MICs were recorded 7 days later and were the lowest drug concentration in which no colour change was seen. MMCs were determined at the time of recording the initial MICs, by transferring $2 \mu \mathrm{l}$ from each well to Hayflick's agar with a 96-pin hand replicator (Intek Services Ltd, Horley, Surrey) and incubating the plates either aerobically or in a $\mathrm{CO}_{2}$-enriched atmosphere (Gaspak, BBL) at $36^{\circ} \mathrm{C}$. MMCs were defined as the lowest concentration to inhibit mycoplasmal growth completely as judged by microscopy after incubation for at least 4 days. Antibiotic susceptibility tests in the presence of a combination of specific M. fermentans PG-18 antiserum and guinea-pig complement diluted to achieve concentrations that were just subinhibitory to $M$. fermentans PG-18 (see above) were performed on certain classes of drug to detect possible synergy. In these tests, $0.05 \mathrm{ml}$ of $M$. fermentans PG-18 antiserum diluted 1 in 32 in Hayflick's broth and $0.05 \mathrm{ml}$ of guinea-pig serum (diluted 1 in 16) were substituted for the $0.1 \mathrm{ml}$ of Hayflick's broth in the MIC tests to give final dilutions of 1 in 128 and 1 in 64, respectively. MMC tests in the presence of antiserum and complement were performed as described above for tests without these immune components.

\section{Induction of aminoglycoside resistance in $M$. fermentans}

Development of resistance and cross-resistance to aminoglycosides in $M$. fermentans strains PG-18 and
KL4 (aminoglycoside-sensitive) were studied in vitro. Tubes containing 1-ml volumes of streptomycin, kanamycin, gentamicin, neomycin or tobramycin in a range of concentrations covering their respective MICs were inoculated with $0.2 \mathrm{ml}$ of freshly thawed (from $-70^{\circ} \mathrm{C}$ ) cultures diluted to contain $c .10^{4} \mathrm{cfu} / \mathrm{ml}$ and incubated at $36^{\circ} \mathrm{C}$. A $0 \cdot 2-\mathrm{ml}$ volume of culture from the highest drug concentration showing an acid colour change was transferred to a fresh series of tubes of drugcontaining broth. Such transfers were repeated at 4day intervals, after which MICs of aminoglycosides for mycoplasmas growing in the highest concentration of drug were compared with those of the parent cultures (PG-18 or KL4). The identities and purities of all resistant variants were checked by testing inhibition of growth by specific antiserum and by plating cultures on inhibitor-free mycoplasma agar.

The stability of the induced aminoglycoside resistance was determined in each case by repeated passage of the resistant variants in aminoglycosidefree broth.

\section{Results}

The in-vitro susceptibilities of 14 strains of $M$. fermentans from various sources to 15 classes of antimicrobial agent are shown in table I. Five classes of agent showed good activity: tetracyclines (initial MIC range $<0.025-0.5 \mathrm{mg} / \mathrm{L}$ ); lincosamides $(0.025-0.25 \mathrm{mg} / \mathrm{L})$; fluoroquinolones $(0.025-$ $0.25 \mathrm{mg} / \mathrm{L})$; tiamulin hydrogen fumarate $(0.005-$ $0.05 \mathrm{mg} / \mathrm{L})$; and mupirocin $(<0.0025-0.01 \mathrm{mg} / \mathrm{L})$. Azithromycin (initial MIC range 0.0025-0.05 mg/L) was strikingly more active than erythromycin (MIC $0 \cdot 05-50 \mathrm{mg} / \mathrm{L}$ ) or clarithromycin (MIC $1->10 \mathrm{mg}$ / L). In terms of mycoplasmacidal activity, the fluoroquinolones, in particular ciprofloxacin (MMC90 $0.1 \mathrm{mg} / \mathrm{L}$ ), the diterpine tiamulin (MMC90 0.1 mg/L), mupirocin (MMC90 0.025 mg/L) and azithromycin (MMC90 0.25 mg/L), were the most effective agents. The tetracyclines and lincosamides were predominantly mycoplasmastatic agents against $M$. fermentans, the cidal concentration being up to 100 -fold or up to 40-fold higher, respectively, than the initial MICs. As expected, all strains of $M$. fermentans were resistant to ampicillin (MIC $>2500 \mathrm{mg} / \mathrm{L}$ ).

Synergy was not observed between any class of antimicrobial agent and specific $M$. fermentans PG-18 antiserum plus guinea-pig complement, although the colour changes denoting the end-point of MIC tests containing these reagents was markedly retarded (table II). Subculture of these tests on mycoplasma agar at the time of recording the initial MICs showed this delay to be associated with large reductions in mycoplasmas ( $<50 \mathrm{cfu} / 2-\mu 1$ sample) from wells containing specific antiserum and complement compared with confluent mycoplasmal growth from the control wells.

Marked differences were observed in the susceptibility of M.fermentans strains to the aminoglycosides 


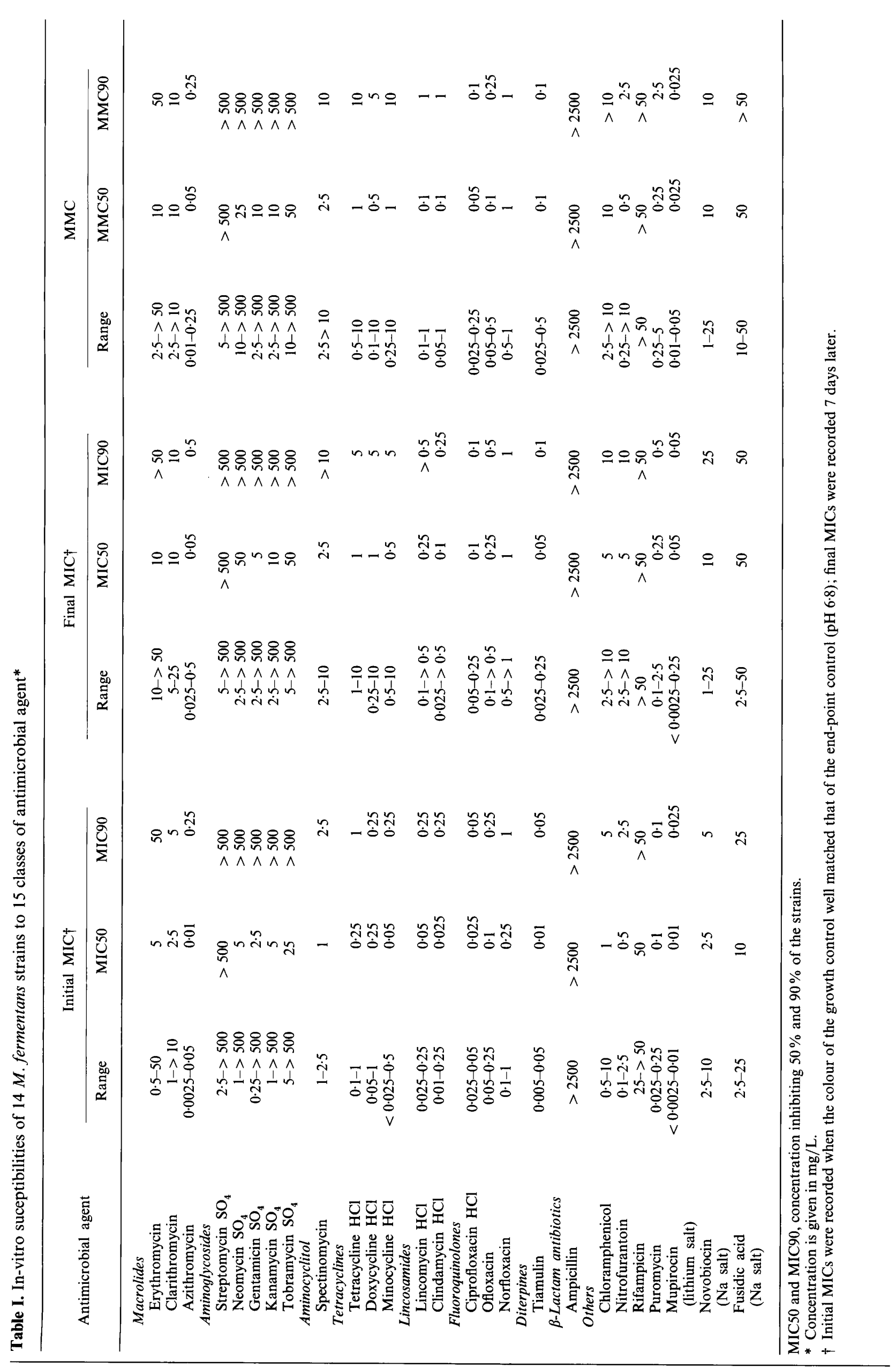


Table II. Antibiotic susceptibilities of $M$. fermentans PG-18 in the absence or presence of specific antiserum and guinea pig complement

\begin{tabular}{llll}
\hline & & MIC $(\mathrm{mg} / \mathrm{L})$ \\
Antimicrobial & & \multicolumn{2}{c}{ With antiserum and complement } \\
\cline { 2 - 4 } agent & $\begin{array}{c}\text { Without antiserum } \\
\text { or complement* }\end{array}$ & 3 days & 7 days \\
\hline Erythromycin & 1 & $<0.25$ & 1 \\
Azithromycin & 0.0025 & $<0.0025$ & 0.0025 \\
Streptomycin & 2.5 & $<0.25$ & 2.5 \\
Gentamicin & 1 & $<0.25$ & 0.5 \\
Doxycycline & 0.25 & $<0.025$ & 0.25 \\
Ciprofloxacin & 0.025 & $<0.025$ & 0.025 \\
Lincomycin & 0.05 & $<0.0025$ & 0.1 \\
Mupirocin & 0.025 & $<0.025$ & 0.025 \\
& & & \\
\hline
\end{tabular}

Table III. MICs (mg/L)* of five aminoglycoside antibiotics for various $M$. fermentans strains

\begin{tabular}{|c|c|c|c|c|c|}
\hline \multirow[b]{2}{*}{ Aminoglycoside } & \multicolumn{2}{|c|}{ Human isolates $1952-1967$} & \multicolumn{2}{|c|}{ Human isolates $1989-1992$} & \multirow{2}{*}{$\begin{array}{l}\text { Cell culture isolates } 1982-1992 \\
(\text { cell-free media; } n=5)\end{array}$} \\
\hline & $\begin{array}{l}\text { cell-free media } \\
\quad(n=4)\end{array}$ & $\begin{array}{l}\text { cell cultures } \\
\quad(\mathrm{n}=2)\end{array}$ & $\begin{array}{l}\text { cell-free media } \\
\quad(\mathrm{n}=2)\end{array}$ & $\begin{array}{l}\text { cell cultures } \\
\quad(\mathrm{n}=1) \dagger\end{array}$ & \\
\hline Streptomycin & $2 \cdot 5$ & $>500$ & $>500$ & $>500$ & $>500$ \\
\hline Neomycin & $2 \cdot 5-5$ & $0 \cdot 5-5$ & 5 & $>500$ & $>500$ \\
\hline Kanamycin & $2 \cdot 5$ & $0 \cdot 25-1$ & 1 & $>500$ & $>500$ \\
\hline Gentamicin & $0 \cdot 5-1$ & $0 \cdot 25-5$ & $2 \cdot 5$ & $>500$ & $>500$ \\
\hline Tobramycin & $5-25$ & 5 & $10-25$ & $>500$ & $250->500$ \\
\hline
\end{tabular}

* Initial MICs, recorded when the colour of the infected control well = end point control (pH 6.8).

$\dagger$ Incognitus strain.

Table IV. Development of resistance and cross-resistance to aminoglycosides in $M$. fermentans KL4 in vitro

\begin{tabular}{|c|c|c|c|c|c|c|}
\hline \multirow{2}{*}{ Aminoglycoside } & \multicolumn{6}{|c|}{ MIC (mg/L) for variants isolated from broth containing } \\
\hline & $\begin{array}{l}\text { Strep } 500 \mathrm{mg} / \mathrm{L} \\
(5 \text { th passage })\end{array}$ & $\begin{array}{c}\text { Neo } 500 \mathrm{mg} / \mathrm{L} \\
(5 \text { th passage })\end{array}$ & $\begin{array}{c}\mathrm{Kan} 200 \mathrm{mg} / \mathrm{L} \\
(8 \mathrm{th} \text { passage })\end{array}$ & $\begin{array}{c}\text { Tob } 500 \mathrm{mg} / \mathrm{L} \\
\text { (7th passage) }\end{array}$ & $\begin{array}{c}\text { Gent } 500 \mathrm{mg} / \mathrm{L} \\
\text { (14th passage) }\end{array}$ & Parent strain \\
\hline Streptomycin & $>500$ & $2 \cdot 5$ & 5 & 5 & 5 & $2 \cdot 5$ \\
\hline Kanamycin & 10 & $>500$ & 250 & $>500$ & 500 & 5 \\
\hline Gentamicin & 5 & $>500$ & $>500$ & $>500$ & $>500$ & $2 \cdot 5$ \\
\hline Neomycin & 25 & $>500$ & 250 & $>500$ & 500 & 25 \\
\hline Tobramycin & 250 & $>500$ & 250 & $>500$ & 125 & 50 \\
\hline
\end{tabular}

Strep, streptomycin; Neo, neomycin; Kan, kanamycin; Tob, tobramycin; Gent, gentamicin. (Similar results were obtained with M. fermentans PG-18.)

(table III). The G strains isolated in 1950 and rheumatoid strains (KL4 and KL8) isolated around 1967 in cell-free medium, were susceptible to all the aminoglycosides tested. The bone marrow strains (E10 and Z62) which were isolated during the 1960 s with the aid of cell cultures containing penicillin and streptomycin to suppress bacterial contamination were resistant to $>500 \mathrm{mg}$ of streptomycin/L but susceptible to the other aminoglycosides. Strains GIM (joint isolate) and BRO (urethral isolate) isolated in 1992 without the use of cell cultures were also more resistant to streptomycin than to other aminoglycosides whereas $M$. fermentans incognitus and all of the cell-culture isolates were resistant to all the aminoglycosides. All strains were susceptible to the aminocyclitol, spectinomycin (initial MIC range $1-2.5 \mathrm{mg} / \mathrm{L}$ ).
Resistance to streptomycin and neomycin (MIC $>500 \mathrm{mg} / \mathrm{L})$ emerged within five passages in broth containing the appropriate aminoglycoside (table IV). Resistance to tobramycin $(\mathrm{MIC}>500 \mathrm{mg} / \mathrm{L})$ emerged after seven passages in tobramycin-containing broth and to kanamycin (MIC $>250 \mathrm{mg} / \mathrm{L}$ ) after eight passages in kanamycincontaining broth. Resistance to gentamicin $(\mathrm{MIC}>500 \mathrm{mg} / \mathrm{L})$ was observed only after 14 passages in gentamicin-containing broth. Development of streptomycin resistance was associated with increased resistance to tobramycin but not to the other aminoglycosides tested. In contrast, variants resistant to neomycin, kanamycin, tobramycin or gentamicin were cross-resistant to these aminoglycosides but remained susceptible to streptomycin (table IV). In all 
but one case, resistance persisted for at least 17 passages in aminoglycoside-free broth.

\section{Discussion}

There are relatively few reports of the antimicrobial susceptibilities of $M$. fermentans. In the most comprehensive study, ${ }^{14}$ the susceptibilities of $24 \mathrm{M}$. fermentans strains from various sources to 10 antimicrobial agents were compared. The results of the current study are broadly consistent with earlier results, despite differences in the MIC methods used in the different laboratories, and also provide new data on previously unreported compounds.

Most striking was the greater anti- $M$. fermentans activity of azithromycin than that of the related macrolides, erythromycin and clarithromycin. Since mycoplasmacidal concentrations of azithromycin are likely to be achieveable in human blood and tissues, this antibiotic should be considered for the treatment of systemic $M$. fermentans infections in man, particularly as it persists in serum, is concentrated within tissues and penetrates mammalian cells, ${ }^{28}$ which are all sites of $M$. fermentans infection. ${ }^{11,13,29}$ The importance of adequate blood and tissue levels of antibiotics was also stressed by Hayes et $a .^{14}$ who concluded that drugs which satisfy those criteria and which are sufficiently active against $M$. fermentans for human use include ciprofloxacin, levofloxacin (not tested in the current study), clindamycin, lincomycin, doxycycline and tetracycline.

The fluoroquinolones, together with the veterinary antibiotic tiamulin and the topical antibiotic mupirocin, appear to be mycoplasmacidal at concentrations close to the MIC. Tiamulin is not licensed for human use and mupirocin is unstable in vivo. ${ }^{30}$ However, these drugs and azithromycin might offer alternative means of eradicating $M$. fermentans from tissue culture cells. Ciprofloxacin has already been found to be effective in this respect. ${ }^{31}$

Mycoplasma infections may be very difficult to eradicate from immunocompromised patients. ${ }^{32,33}$ The persistance of $M$. pneumoniae in a patient with hypogammaglobulinaemia despite prolonged treatment with tetracycline, erythromycin and doxycycline has been reported. ${ }^{34}$ It has been suggested ${ }^{32,34}$ that in hypogammaglobulinaemic patients infected with $M$. pneumoniae, antibiotic treatment should be supplemented with plasma obtained from immunocompetent patients known to have high circulating antibody. Elimination of Ureaplasma urealyticum has been achieved in an aggammaglobulinaemic patient with simultaneous antibiotic and hyperimmune goat antiserum (P. M. Furr, personal communication). Such cures could be due either to synergy between certain antibiotics and specific antibodies in the presence of serum complement or to reductions in the mycoplasma load sufficient for cellular immune mechanisms to cope with the infection. Since synergy was not found in the current study, but mycoplasma numbers were markedly reduced by the antiserum and guinea-pig complement, the second of these hypotheses seems more likely.

Marked resistance of some $M$. fermentans strains to certain aminoglycosides has been reported previously.${ }^{14,35}$ In those studies, $M$. fermentans incognitus and other $M$. fermentans strains derived from urine sediments from AIDS patients were compared with isolates from an outbreak of acute respiratory infection in Canada, an isolate from a patient with leukaemia, ${ }^{2}$ various cell culture isolates and the type strain PG-18. Significant differences in the broth MICs of aminoglycosides for $M$. fermentans strains from different sources were not apparent. However, the present results show clearly that early $M$. fermentans isolates obtained in cell-free media were susceptible to all of the aminoglycosides tested, whereas strains isolated in cell cultures were highly resistant to streptomycin, an aminoglycoside commonly incorporated in tissue culture media to suppress bacterial contamination. The experiments also showed that $M$. fermentans strains obtained more recently without the use of cell cultures were also resistant to streptomycin, suggesting that resistance to streptomycin had been acquired through use of the drug. These strains and the earlier isolates were all susceptible to the deoxystreptamine group of aminoglycosides (neomycin, kanamycin, gentamicin, tobramycin). However, $M$. fermentans incognitus and all strains derived from cell cultures showed cross-resistance to all aminoglycosides tested. In the case of the cell culture strains, this may have been due to exposure to streptomycin and other aminoglycosides during attempts to remove bacterial or mycoplasmal contaminants from tissue culture cell stocks, as kanamycin, gentamicin and neomycin are often used for this purpose. ${ }^{10}$ The demonstration of aminoglycoside cross-resistance in $M$. fermentans incognitus throws doubt on the origin of this strain since it was detected originally during transfection studies with NIH/3T3 cells.

To ascertain the ease with which $M$. fermentans develops resistance to individual aminoglycosides and the cross-resistance patterns which arise following development of resistance to particular aminoglycosides, habituation experiments were performed in vitro. These tests showed that high resistance to the streptidine-containing aminoglycoside, streptomycin, developed within five passages in streptomycin-containing broth, and that such variants were not crossresistant to deoxystreptamine-containing aminoglycosides, other than tobramycin. Conversely, deoxystreptamine-containing aminoglycosides induced cross-resistance to other members of that group, but not to streptomycin. These induced resistances were generally stable, indicating that once resistance had developed it was permanent. The mechanisms by which aminoglycoside resistance developed were not studied. 
These results indicate that aminoglycoside resistance in $M$. fermentans is associated with previous exposure to these antibiotics, but that exposure to streptomycin alone does not trigger multiple resistance. The use of streptomycin and other aminoglycosides in human medicine and the frequent inclusion of some of these drugs in cell cultures to combat bacterial and mycoplasmal contamination may account for the high single or multiple aminoglycoside resistances in recent $M$. fermentans isolates. The rapid development of multiple aminoglycoside resistance demonstrated in vitro indicates that such resistance could develop in patients treated with any aminoglycoside. Naturally susceptible $M$. fermentans strains could also develop multiple aminoglycoside resistance during the isolation process if tissue cultures

\section{References}

1. Ruiter M, Wentholt HMM. The occurrence of a pleuropneumonia-like organism in fuso-spirillary infections of the human genital mucosa. J Invest Dermatol 1952; 18: 313-325.

2. Murphy WH, Bullis C, Ertel IJ, Zarafonetis CJD. Mycoplasma studies on human leukemia. Ann NY Acad Sci 1967; 143 : 544-556.

3. Williams MH. Recovery of mycoplasmas from rheumatoid synovial fluid. In: Third Pfizer International Symposium on "Rheumatic Diseases". Edinburgh, Edinburgh University Press. 1968: 171-181.

4. Gabridge MG, Abrams GD, Murphy WH. Lethal toxicity of Mycoplasma fermentans for mice. J Infect Dis 1972; 125 : 153-160.

5. Hannan PCT, Driver SW. Arthritis in mice induced with Mycoplasma fermentans isolated from the joint of a patient with rheumatoid arthritis. IOM Letters Vol. 1. Eighth International Congress of the International Organisation for Mycoplasmology (IOM), 8-12 July, Istanbul, Turkey. 1990: 349.

6. Cole BC, Ward JR, Smith CB. Studies on the infectious etiology of rheumatoid arthritis. Arthritis Rheum 1973; 16: 191-198.

7. Mårdh PA, Nilsson FJ, Bjelle A. Mycoplasmas and bacteria in synovial fluid from patients with arthritis. Ann Rheum Dis $1973 ; 32$ : 319-325.

8. Windsor GD, Nicholls A, Maini RN, Edward DGff, Lemcke RM, Dumonde DC. Search for mycoplasma in synovial fluids from patients with rheumatoid arthritis. Ann Rheum Dis 1974; 33: 70-74.

9. Zheverzheeva IV, Koptelova EI, Neustroeva VV, Vul'fovich $\mathrm{IuV}$, Iaguzhinskaia OE. Indication of mycoplasmas in the synovial fluid of rheumatoid arthritis patients. $Z$. $H$ Mikrobiol Epidemiol Immunobiol 1983; Sept. (9): 63-66.

10. Barile MF. Mycoplasma-tissue cell interactions. In: Tully JG, Whitcomb RF (eds) The mycoplasmas, vol. II. Human and animal mycoplasmas. New York, Academic Press. 1979: 425-474.

11. Lo S-C, Shih JW-K, Yang N-Y, Ou C-Y, Wang RY-H. A novel virus-like infectious agent in patients with AIDS. $A m J$ Trop Med Hyg 1989; 40: 213-226.

12. Lo S-C, Wang RY-H, Newton PB, Yang N-Y, Sonoda MA, Shih JW-K. Fatal infection of silvered leaf monkeys with a virus-like infectious agent (VLIA) derived from a patient with AIDS. Am J Trop Med Hyg 1989; 40: 399-409.

13. Lo S-C, Dawson MS, Newton PB et al Association of the virus-like infectious agent originally reported in patients with AIDS with acute fatal disease in previously healthy non-AIDS patients. Am $J$ Trop Med Hyg 1989; 41: $364-376$.

14. Hayes MM, Foo H-H, Kotani H, Wear DJ, Lo S-C. In vitro antibiotic susceptibility testing of different strains of Mycoplasma fermentans isolated from a variety of sources. Antimicrob Agents Chemother 1993; 37: 2500-2503.

15. Cassell GH, Yanez A, Duffy LB et al. Detection of Mycoplasma containing streptomycin or other aminoglycosides of the neomycin group were used, although such strains could be tissue culture contaminants. Since the antibiotic treatment history of the AIDS patient from which $M$. fermentans incognitus was isolated is unknown (S.-C. Lo, personal communication), the multiple aminoglycoside resistances seen in $M$. fermentans incognitus could be due to any of these possibilities.

The author thanks Dr G. D. Windsor and Helena M. Windsor at Mycoplasma Experience Ltd for providing facilities, materials and the $M$. fermentans cell culture isolates, Dr Shyh-Ching Lo, Professor Christiane Bébéar, Dr W. H. Murphy and Dr Merfyn H. Williams for the human $M$. fermentans strains, Miss Amanda Hicks and Mrs Nicolette Masson for help in obtaining scientific information, Mrs Sue Hayes for preparing the manuscript and SmithKline Beecham Pharmaceuticals for the sample of mupirocin. fermentans in the respiratory tract of children with pneumonia. IOM Letters Vol 3, 10th International Congress of the International Organisation for Mycoplasmology (IOM), Bordeaux, France, July 19-26. 1994: 456.

16. Katseni VL, Gilroy CB, Ryait BK et al. Mycoplasma fermentans in individuals seropositive and seronegative for HIV-1. Lancet $1993 ; 341$ : 271-273.

17. LO S-C, Tsai S, Benish JR, Shih JW-K, Wear DJ, Wong DM. Enhancement of HIV-1 cytocidal effects on CD4 + lymphocytes by the AIDS-associated mycoplasma. Science 1991; 251: 1074-1076.

18. Lemâitre M, Guetard D, Hénin Y, Montagnier L, Zerial A. Protective activity of tetracycline analogs against the cytopathic effect of the human immunodeficiency viruses in CEM cells. Res Virol 1990; 141 : 5-16.

19. Stewart SM, Burnet ME, Young JE. In-vitro sensitivity of strains of mycoplasmas from human sources to antibiotics and to sodium aurothiomalate and tylosin tartrate. $J$ Med Microbiol 1969; 2 : 287-292.

20. Braun P, Klein JO, Kass EH. Susceptibility of genital mycoplasmas to antimicrobial agents. App Microbiol 1970; 19: $62-70$.

21. Laborde M. Étude de la sensibilité aux antibiotiques de 34 souches de mycoplasmes a grandes colonies. Pathol Biol 1977; 25: 541-546.

22. Fallon RJ, Brown WM. In-vitro sensitivity of legionellas, meningococci and mycoplasmas to ciprofloxacin and enoxacin. J Antimicrob Chemother 1985; 15: 787-789.

23. Freundt EA. Modified Hayflick medium: in culture media for classic mycoplasmas. In: Razin S, Tully JG (eds) Methods in mycoplasmology, vol 1. New York, Academic Press. 1983: 130 .

24. Friis NF. Some recommendations concerning primary isolation of Mycoplasma suipneumoniae and Mycoplasma flocculare: a survey. Nord Vet Med 1975; 27 : 337-339.

25. Clyde WA. Mycoplasma species identification based upon growth inhibition by specific antisera. $J$ Immunol $1964 ; 92$ : 958-965.

26. Taylor-Robinson D, Purcell RH, Wong DC, Chanock RM. A colour test for the measurement of antibody to certain mycoplasma species based on the inhibition of acid production. $J$ Hyg 1966; 64: 91-104.

27. Taylor-Robinson D. Mycoplasmas of various hosts and their antibiotic sensitivities. Postgrad Med J 1967; 43 Suppl 43: 100-104.

28. Kirst HA, Sides GD. New directions for macrolide antibiotics: pharmacokinetics and clinical efficacy. Antimicrob Agents Chemother 1989; 33: 1419-1422.

29. Taylor-Robinson D, Davies HA, Sarathchandra P, Furr PM. Intracellular location of mycoplasmas in cultured cells demonstrated by immunocytochemistry and electron microscopy. Int J Exp Pathol 1991; 72: 705-714.

30. Basker MJ, Comber KR, Clayton JP et al. Ethyl monate A: a semisynthetic antibiotic derived from pseudomonic acid $A$. In: Nelson JD, Grassi C (eds) Current chemotherapy and infectious disease. Proceedings of the 11 th International 
Congress on Chemotherapy and the 19th Interscience Conference on Antimicrobial Agents and Chemotherapy. Washington, American Society of Microbiology. 1980: $471-473$.

31. Schmitt K, Daubener W, Bitter-Suermann D, Hadding U. A safe and efficient method for elimination of cell culture mycoplasmas using ciprofloxacin. $J$ Immunol Methods 1988; 109: 17-25.

32. Brunner $\mathrm{H}$, Laber $\mathbf{G}$. Chemotherapy of mycoplasma infections In: Razin S, Barile MF (eds) The mycoplasmas, vol IV. Mycoplasma pathogenicity. London, Academic Press. 1985: 403-450.
33. Furr PM, Taylor-Robinson D, Webster ADB. Mycoplasmas and ureaplasmasin patients with hypogammaglobulinaemia and their role in arthritis: microbiological observations over twenty years. Ann Rheum Dis 1994; 53: 183-187.

34. Taylor-Robinson D, Webster ADB, Furr PM, Asherson GL. Prolonged persistance of Mycoplasma pneumoniae in a patient with hypogammaglobulinaemia. J Infect 1980; 2: $171-175$.

35. Hayes MM, Wear DJ, Lo S-C. In vitro antimicrobial susceptibility testing for the newly identified AIDS-associated mycoplasma Mycoplasma fermentans (incognitus strain). Arch Pathol Lab Med 1991; 115: 464-466. 